Disponível em

http://www.anpad.org.br/rac

RAC, Rio de Janeiro, v. 18, n. 6, art. 3, pp. 795-812, Nov./Dez. 2014

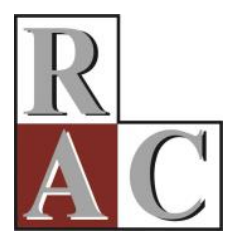

\title{
Montagem de Agenda no Comitê Itajaí: Uma Aplicação do Modelo de Kingdon
}

Agenda Setting at the Comitê Itajaí: An Application of the Kingdon Model

Marcello Beckert Zapelini

E-mail: mbzapelini@hotmail.com Universidade do Estado de Santa Catarina - ESAG/UDESC Av. Madre Benvenuta, 2037, Itacorubi, 88035-001, Florianópolis, SC, Brasil. 


\title{
Resumo
}

Este artigo tem o objetivo de estudar a montagem de agenda na formulação do Plano de Bacia Hidrográfica no Comitê Itajaí. Em termos metodológicos, consiste numa pesquisa de estudo de caso qualitativo, documental e de campo, que utilizou, como métodos de coleta de dados, a pesquisa documental e a entrevista. Estudou-se o caso da decisão de cobrança pelo uso dos recursos hídricos, ao qual se aplicou o modelo de múltiplos fluxos Kingdon (2003) com o intuito de compreender a dinâmica da ação dos agentes envolvidos, em que a combinação do fluxo de problemas, do fluxo de políticas e do fluxo político levou à abertura de uma janela de política. Assim, os usuários de recursos hídricos, atuando como empreendedores de política, utilizaram a janela de política para modificar a fórmula de cobrança originalmente proposta pela diretoria do Comitê, assim, garantindo um instrumento mais adequado aos seus interesses.

Palavras-chave: montagem de agenda; cobrança pelo uso de recursos hídricos; tomada de decisão.

\begin{abstract}
The objective of this article is to study agenda setting during the formulation of the Itajaí River Basin Plan by the Comitê Itajaí (Itajaí Committee). In methodological terms, it consists of a qualitative, documentary and field case study, collecting data through documentary research and interview. The studied case was that of the decision to charge for the use of water resources, to which we applied Kingdon's multiple streams model (2003) in order to understand the dynamics of the involved agents' actions in which the combination of the problem, political and policy streams led to the opening of a policy window. Hence, water resource users, acting as policy entrepreneurs, made use of the policy window to modify the formula for charging originally proposed by the Committee's board of directors, thus ensuring a more appropriate instrument for their interests.
\end{abstract}

Key words: agenda setting; water resource use charging; decision making. 


\section{Introdução}

Este artigo tem por objetivo analisar a montagem de agenda no caso do processo de tomada de decisão a respeito da cobrança pelo uso dos recursos hídricos no Comitê Itajaí (Santa Catarina). Para tanto, valeu-se de quadro teórico formado pelo modelo de múltiplos fluxos de John Kingdon (2003), originalmente proposto em 1984, com a modificação proposta por Zahariadis (1998). Este modelo busca compreender de que forma questões são inseridas na agenda de discussão de um grupo de agentes envolvidos no processo de policy-making e, na versão de Zahariadis, expande-se para abranger o processo decisório. Conforme Thurber, em seu prefácio a Kingdon (2003), trata-se de um modelo inestimável para compreender de que forma uma ideia começa a evoluir para uma política pública. Travis e Zahariadis (2002) o encaram como um grande avanço no estudo das políticas, mas reconhecem que, apesar dos elogios, foi pouco aplicado empiricamente fora dos Estados Unidos. Este artigo busca fazer uma aplicação no Brasil, da mesma forma que Chow (2014) realizou uma aplicação em Hong Kong.

A agenda é um dos elementos mais importantes no ciclo de política pública (Zahariadis, 1998), um recurso heurístico utilizado para compreender o processo pelo qual uma intenção é transformada em ação por parte de um órgão público ou publicizado, chamado a cumprir objetivos públicos. Assim, controlar a montagem da agenda significa determinar o que será discutido, decidido e posto em prática (Majone, 2006), constituindo-se, dessa forma, em um poder de definir os rumos da ação pública em um determinado contexto ou meio social.

A legislação brasileira definiu que a efetiva gestão dos recursos hídricos compete a órgãos específicos, os comitês de bacia hidrográfica. Estes devem decidir de modo participativo e democrático os rumos da gestão das águas (como observado, entre outros, por Jacobi, 2006a, 2006b), utilizando-se, para tanto, de instrumentos definidos pela lei, entre os quais se tem a cobrança pelo uso. Esta é vista como uma forma de conferir valor econômico à água, racionalizar seu uso e garantir recursos financeiros para obras da bacia e funcionamento do aparato gestor (Dias \& Barros, 2008). Dessa maneira, a cobrança é definida como um dos elementos da agenda decisória da gestão de recursos hídricos, que deve constar do plano de bacia hidrográfica.

Em Santa Catarina, o Comitê Itajaí, constituído na década de 1990, tem buscado constituir os diferentes instrumentos de gestão de recursos hídricos, tendo concluído o processo de definição do plano de bacia em 2010. Embora este contemplasse a instituição da cobrança, no momento da assembleia que deveria aprová-lo, sua discussão da cobrança tornou-se um embate entre forças politicamente organizadas, com posições contrárias em relação ao instrumento. Como resultado, o plano foi aprovado, mas não o modelo de cobrança por ele defendido.

Este artigo aplica a esse evento o modelo de Kingdon e discute como os diferentes fluxos se conjugaram para promover a mudança na fórmula da cobrança. Baseado em uma pesquisa feita para a tese de doutorado do autor, o artigo está dividido em um referencial teórico no qual se analisam os conceitos de arena decisória e de montagem de agenda conforme Kingdon, uma breve explicação da metodologia de pesquisa, a análise do caso empírico e as considerações finais.

\section{A Montagem de Agenda: O Modelo de Kingdon}

Para a tomada de decisão em um contexto político e participativo, como é o caso dos comitês de bacia hidrográfica, é preciso, entre outros aspectos, definir um contexto (arena decisória) e uma listagem de assuntos a serem debatidos e decididos. Assim, pretende-se aqui trabalhar com os conceitos de arena decisória e de montagem de agenda. 
Decisões, afirmam Hunt e Magenau (1984), resultam de uma transação entre pessoas e problemas num cenário. Para os efeitos do tratamento dado ao assunto, o termo cenário será substituído por arena. De acordo com Souza (2007), o modelo de arenas sociais considera a política pública como o resultado de iniciativas de empreendedores políticos (ou empreendedores de políticas públicas) capazes de convencer o governo de que algo deve ser feito em relação a um dado problema, por meio da divulgação de indicadores, pela ocorrência de desastres ou pela repetição dos mesmos problemas, ou pelo feedback que indica que a política atual não está gerando o resultado adequado. Esses empreendedores formam policy communities, ou seja, comunidades de especialistas que se dispõem a investir recursos na expectativa de retornos futuros em termos de políticas públicas; normalmente, esses empreendedores formam redes sociais para alavancar suas capacidades individuais (Souza, 2007).

Ostrom (2007) afirma que as arenas de política (ou arenas de ação) são unidades conceituais que podem ser usadas para analisar, prever e explicar o comportamento dos atores em situações de definição de políticas públicas. Em sua concepção, uma arena abrange sete conjuntos de variáveis: participantes, posições, resultados, relação entre as ações e os resultados, controle exercido sobre o processo pelos participantes, informações e custos e benefícios associados aos resultados. As arenas de ação são definidas pela autora como uma unidade conceitual complexa que abrange atores e situações de ação, formando um espaço social em que as pessoas interagem, intercambiam bens e serviços entre si, resolvem problemas, dominam uns aos outros e envolvem-se em lutas ou disputas (Ostrom, 2007). Para compreender a arena de política, então, é necessário identificar os atores envolvidos no processo de política pública, determinar sua posição nesse processo, definir as ações permitidas e os resultados que estas podem gerar (bem como as conexões causais entre as mesmas), o nível de informação disponível e a capacidade de cada ator de realizar escolhas.

Conquanto o modelo de arena de política de Ostrom seja intuitivamente simples, baseando-se nos construtos da teoria da escolha racional, pode ser criticado por desconsiderar os arranjos políticos entre os atores; embora adequado para a análise de um processo decisório baseado no modelo racionalanalítico, não é de todo aplicável ao da polis (Stone, 2002), mais adequado para um processo político. Dessa maneira, trabalha-se aqui com uma perspectiva das arenas decisórias compostas por atores, que, num espaço institucional definido por regras e permeado por arranjos de poder, analisam situaçõesproblema em busca de soluções satisfatórias. Ou seja, buscam soluções que não obedecem ao imperativo (próprio do modelo racional-analítico) da maximização dos interesses, e sim à conciliação de tais interesses de maneira a satisfazer as expectativas de todos os atores envolvidos (idealmente) ou dos que preponderam no processo (embora, mesmo neste caso, os atores dominantes devam abdicar de alguns interesses para convencer os demais a aceitar suas propostas).

Nessas arenas, de acordo com Valencio (2009), um risco permanentemente presente é o da participação se transformar em autoridade, ou seja, o de que atores utilizem os canais de participação da arena decisória para fazer com que prevaleçam seus interesses e demandas sobre os demais. Para a autora:

A apologia da participação social é, de fato, a dissimulação do poder nas arenas de discussão e deliberação, fruto de uma sociedade que escamoteia sistematicamente suas assimetrias e desvia os olhares do conteúdo das soluções postas em curso, sempre favoráveis aos mesmos interesses. (Valencio, 2009, p. 87).

Definindo-se alguns dos elementos supracitados, pode-se conceituar o espaço institucional como o subconjunto da sociedade em que as instituições relevantes para o processo decisório social operam; as instituições são, conforme Ostrom (2007), conceitos partilhados por seres humanos e utilizados em situações organizadas por regras (prescrições mutuamente reconhecidas, adotadas por todos e reforçadas por atores encarregados de acompanhar a conduta, bem como impor sanções aos demais), normas (ou seja, prescrições que os participantes do processo reforçam por si mesmos) e estratégias (que são os planos que os atores fazem dentro da estrutura de incentivos produzida por normas, regras e expectativas do comportamento de outrem). 
Uma situação-problema consiste numa situação indesejável que, na percepção das pessoas ou grupos de interesse, pode ser modificada por uma ação governamental (Birkland, 2005). Esta ação, no modelo aqui proposto, deve ser considerada como pública, envolvendo a atuação de um governo, mas não se restringindo a ele, pois pode abranger diferentes atores nela envolvidos. Por soluções satisfatórias, entendem-se as ações de política que permitem estruturar as relações e coordenar comportamentos na busca de propósitos coletivos (Stone, 2002), não dentro de um imperativo racionalanalítico de maximização dos benefícios, mas numa perspectiva de racionalidade limitada (como proposto por Simon, 1997). Quanto aos interesses, podem ser adotadas as perspectivas de Schattschneider (1975) e Stone (2002), que os entendem como motivos, intenções e desejos de pessoas, que são discutidos politicamente em uma situação em que pessoas imaginam ou experimentam efeitos e tentam influenciá-los.

A montagem de agenda é crucial dentro do processo decisório, e é um dos momentos em que se verifica o exercício do poder numa organização. De fato, em sua análise do poder, Bachrach e Baratz (1962) deixam claro que essa dimensão se verifica na capacidade de um ator em retirar da agenda decisória aquilo que não interessa a ele discutir, ainda que possa ser de interesse ou relevante para aqueles sobre os quais ele exerce seu poder. Assim, o exercício de poder no processo decisório envolve a capacidade de selecionar quais serão as questões que farão parte da agenda. Por sua vez, Hollis (1999) afirma que é possível afetar diversos elementos dentro de uma agenda, mudando a redação e a ordem dos itens a serem discutidos e retirando-lhe assuntos e questões antes que se chegue ao processo decisório.

Kingdon (2003) afirma que a expressão agenda possui diferentes significados. Em seu modelo, trata-se da "lista de assuntos ou problemas para os quais os membros do governo e as pessoas que, embora estejam fora do governo, dedicam atenção seriamente em algum momento" (p. 3). De modo similar, uma agenda pública consiste em um conjunto de questões às quais o público dedica atenção (Jones \& Baumgarten, 2004). Birkland (2005) define a agenda como a lista das coisas que são discutidas por (e, às vezes, objeto de ações de) uma instituição, meios de comunicação de massa ou o público como um todo; em outra definição do mesmo autor, ela é vista como uma coleção de problemas, de entendimento de causas, de símbolos, de soluções e de outros elementos de problemas públicos que chegam ao conhecimento do público e dos governantes. Para Page (2006), a noção de agenda implica em assuntos ou questões sujeitas a alguma forma de deliberação, mas, eventualmente, as políticas públicas podem ser definidas sem essa deliberação consciente - neste caso, trata-se da não decisão definida por Bachrach e Baratz (1962).

Birkland (2005) esclarece que as agendas existem em todas as esferas e níveis de governo, devendo-se reconhecer diferentes níveis: em primeiro lugar, existe o universo de agenda, que consiste em tudo o que pode, eventualmente, ser trazido à discussão em uma sociedade ou sistema político; este sistema abrange a agenda sistêmica, que diz respeito às ideias mais ou menos aceitáveis em termos políticos; o terceiro nível corresponde à agenda institucional, um subconjunto que abrange a lista de itens e questões que explicitamente são consideradas pelos tomadores de decisão com seriedade; por fim, há a agenda de decisão, que é formada pelos itens que podem ser objeto de ação por parte de um órgão governamental, como regulações, leis, etc.

De acordo com Majone (2006), o poder sobre a agenda pode ser exercido exclusivamente por um indivíduo ou grupo. Assim, o monopólio sobre a definição da agenda implica em possibilidade de obter praticamente qualquer resultado por parte do monopolista, pois este seria capaz de ordenar as opções a serem discutidas pelo grupo votante submetido a uma regra de maioria. Além disso, quando exercido por mais de uma pessoa, o poder de controlar a agenda pode levar a coalizões entre membros de um comitê responsável pela decisão, que teria condições de vetar a discussão de quaisquer elementos ou questões que não fossem de seu interesse (Majone, 2006). Schattschneider (1975) vai ainda mais longe, pois coloca que a capacidade de definir as alternativas de solução é o supremo instrumento de poder; o grupo que consegue controlar a definição dos problemas e das alternativas da agenda, bem como aquele que consegue manter outros fora desta, é o que prevalece no debate sobre a política, de acordo com 
Birkland (2005). Revela-se, assim, uma congruência entre as visões de Schattschneider e de Bachrach e Baratz.

Para Souza (2007), os modelos teóricos de políticas públicas que enfatizam a montagem ou definição de agenda são baseados na ideia de ciclo de política pública; na sua visão, os governos definem que determinados problemas fazem parte de uma agenda quando consideram que é preciso fazer alguma coisa em relação a eles. Conforme Kingdon (2003), a montagem de agenda corresponde a um estágio de pré-decisão, em que determinadas questões são seriamente consideradas em termos de futuras políticas públicas e outras são simplesmente descartadas. Birkland (2005), por sua vez, vê a montagem como o processo pelo qual problemas e possíveis soluções ganham ou perdem a atenção do público em geral ou de uma elite. Howlett e Ramesh (2003) asseveram que, para se compreender o processo de montagem de agenda, é preciso compreender de que maneira indivíduos e/ou grupos apresentam demandas ao governo, como este as responde, e vice-versa, o que envolve compreender os interesses materiais dos atores sociais e estatais, bem como os contextos ideológico e institucional em que operam. Estes autores descrevem diversos modelos de montagem de agenda, mas destacam o modelo de Kingdon, que, segundo eles, é uma abordagem sofisticada, baseada em estudos empíricos por ele realizados no Congresso norte-americano.

Para Kingdon, montar uma agenda consiste em reduzir a lista original de assuntos a serem discutidos, fazendo com que apenas alguns sejam seriamente examinados pelo grupo responsável por uma política pública. Além disso, é preciso distinguir entre a agenda governamental e a de decisão: enquanto a primeira diz respeito a todos os assuntos que chamam atenção de um governo, a segunda consiste naqueles que efetivamente são objeto de ações de decisão (Kingdon, 2003); um problema passa a fazer parte da agenda governamental quando desperta a atenção de formuladores de política, e da agenda decisional quando, dentro da governamental, determinadas questões são desenvolvidas a ponto de se tornarem objeto de decisão por parte desses formuladores (Capella, 2007; Kingdon, 2003).

O modelo de Kingdon (2003) combina uma série de conceitos que podem ser visualizados na Figura 1:

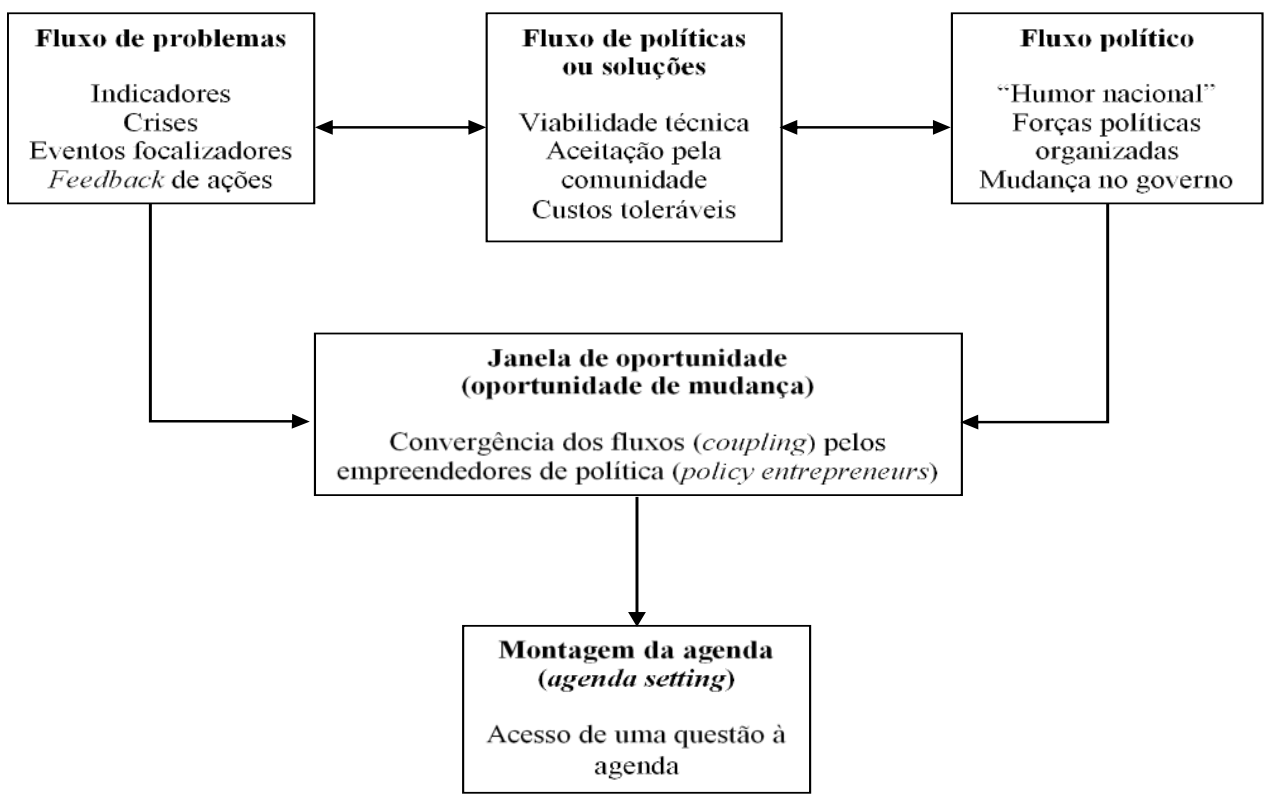

Figura 1. O Modelo de Kingdon para a Montagem de Agenda.

A Fgura 1 mostra como os diferentes fluxos se combinam para abrir a janela de oportunidade, em que os empreendedores de política têm condições de influenciar a agenda governamental. Fonte: Adaptado de Capella, A. C. (2007). Perspectivas teóricas sobre o processo de formulação de políticas públicas. In G. Hochman, M. Arretche, \& E. Marques (Orgs.), Políticas públicas no Brasil (pp. 87-122). Rio de Janeiro: Fiocruz.

Como se pode observar, o modelo é formado por três fluxos que, uma vez combinados (coupled), abrem janelas de oportunidades (policy windows) e permitem a atores - os empreendedores de política 
(policy entrepreneurs) - inserir questões na agenda governamental, de modo a garantir que as mesmas sejam discutidas e transformadas em políticas públicas que os beneficiem (Bakir, 2009; Capella, 2007; Kingdon, 2003); o modelo, então, distingue entre os processos de política (como os três fluxos) e os participantes em tal processo (dos quais os empreendedores são os mais visíveis no tratamento do modelo, mas também se pode falar nos burocratas e administradores e nos líderes políticos).

Chow (2014) constatou que os estudiosos que aplicaram o modelo de Kingdon encaram o processo político como dinâmico e imprevisível, processando-se em um ambiente complexo e ambíguo. Assim, a dinâmica dos fluxos não pode ser prevista, tornando a política algo irracional em comparação com os modelos decisórios influenciados pelo positivismo.

O fluxo de problemas (problem stream), de acordo com Kingdon (2003), consiste nos problemas que se tornam objeto de atenção dos tomadores de decisão não por causa de pressões políticas, mas porque houve alguma mudança nos indicadores monitorados pelo governo, como taxas de mortalidade infantil, custos de programas sociais, etc., por causa de eventos focalizadores, como crises ou desastres naturais, ou símbolos que chamam atenção dos formuladores de políticas, ou pelo feedback fornecido pela população ou por órgãos governamentais a respeito de programas existentes.

Em outras palavras, novos problemas surgiram, ou a resposta dada aos problemas existentes é insuficiente ou inadequada, ou consequências não antecipadas das políticas demandam maior atenção do governo. Segundo Birkland (2005), as mudanças em indicadores, por si mesmas, não suscitam mudanças nas políticas até serem devidamente divulgadas por grupos de interesse, agências governamentais e empreendedores de política, que os usam para defender suas ideias para a população em geral; contudo, segundo esse autor, os eventos focalizadores, como levantam grande interesse do público e dos meios de comunicação, levam à mobilização dos grupos ou do governo em torno das questões que levantam.

O fluxo de políticas ou soluções (policy stream) parte do pressuposto de que existem comunidades de política (policy communities) formadas por especialistas em determinadas áreas de políticas públicas, tanto dentro quanto fora dos governos, que discutem questões que demandam ação governamental, tanto por determinação destes quanto por vontade própria, elaborando e oferecendo à apreciação do público soluções para tais questões, soluções estas que podem ser transformadas em políticas públicas específicas (Kingdon, 2003). Existem, conforme Blankenau (2001), soluções justapostas aos problemas, identificadas e apresentadas por analistas de políticas, líderes políticos e pesquisadores, que devem ser aceitáveis para a comunidade e tecnicamente possíveis, bem como enquadrarem-se nos valores do sistema político. Essas questões e soluções são discutidas dentro dessas comunidades e divulgadas para o governo e população em geral por diferentes canais, de modo a influenciar a discussão geral sobre políticas públicas a serem adotadas em cada questão da agenda. Para que tenham alguma chance de ser adotadas pelos governos, essas políticas devem, em primeiro lugar, ser tecnicamente viáveis (ou seja, é preciso ser possível implementá-las), aceitáveis pelo público (isto é, devem estar de acordo com os valores e anseios da população) e eficientes em termos de custos. Outro fator que contribui para o sucesso na adoção de determinada política é a capacidade da comunidade de política de antecipar restrições futuras à sua proposta. Dessa forma, o número de ideias que efetivamente ultrapassa os limites da comunidade e torna-se objeto de discussão efetiva no sistema mais amplo de política pública é relativamente pequeno; este resultado indica um consenso entre os atores envolvidos, obtido por meio de esforços de persuasão (Kingdon, 2003).

O fluxo político (political stream) opera independentemente (ou seja, ele flui de acordo com suas próprias regras e dinâmica) dos dois anteriores, sendo influenciado pelos humores do público, pelas campanhas e pressões de grupos de interesse, pelos resultados de eleições, pela ideologia dos partidos representados no Poder Legislativo e pela mudança na administração do governo. Esses eventos não devem, entretanto, ser considerados como alheios ao processo de formulação de políticas, pois não se pode dissociar completamente os dois fluxos anteriores dos elementos deste - há uma relação de influência mesmo que sejam, como anteriormente colocado, independentes. O humor nacional indica que o público no país tende a pensar de maneira mais ou menos comum, dando o tom para os líderes políticos sobre o que seus eleitores pensam e valorizam. As pressões de forças políticas organizadas, 
como os grupos de interesse, mobilizam os formuladores de políticas por meio da indicação do que segmentos importantes (ou ativos) da população desejam ou experimentam. Por fim, mudanças no governo e na administração envolvem modificações no pessoal chave dentro dos órgãos governamentais, nas esferas de jurisdição de órgãos administrativos ou das comissões no Poder Legislativo, disputas de poder, etc., indicando, desta forma, situações em que alternativas de política antes desconsideradas como inadequadas ou inviáveis passem a ser valorizadas e discutidas com maior profundidade. Neste fluxo, o consenso entre os atores é obtido por meio de barganhas: eles constroem coalizões por meio de concessões feitas uns aos outros, entrando no jogo sempre que percebem alguma ameaça potencial aos seus interesses (Kingdon, 2003).

Os empreendedores de política, que Kingdon (2003) descreve como advocates que se dispõem a investir tempo e recursos na promoção de seus posicionamentos em troca de ganhos futuros, podem ser encontrados em diferentes pontos do sistema de política, dentro e fora dos governos; eles se caracterizam por serem persistentes, por apresentarem conexões políticas ou habilidades de negociação, bem como por reivindicarem a atenção do governo ou do público, seja por capacidades pessoais, seja por ocuparem posições em que isso esteja atribuído. Para Bakir (2009), esses empreendedores usam o discurso e mobilizam ideias para produzir mudanças nas políticas.

De acordo com Howlett e Ramesh (2003), os empreendedores de política são atores chave no processo político que conseguem dar vazão a certas questões particulares. Esses empreendedores percebem quando os fluxos estão combinados, ou seja, quando ocorre o coupling: são situações em que se abrem janelas de política (policy windows) ou janelas de oportunidade; essas janelas se abrem tanto periódica quanto aleatoriamente (mas, de qualquer forma, não se abrem com grande frequência e não permanecem abertas por muito tempo), e os empreendedores bem preparados são capazes de reconhecer as oportunidades de influenciar a política. Lima e Medeiros (2012) associam os empreendedores de política aos responsáveis por sua implementação, mas, de forma geral, seguem o padrão de Kingdon, que afirma:

Os fluxos separados se juntam em momentos críticos. Um problema é reconhecido, uma solução é desenvolvida e disponibilizada na comunidade de política, uma mudança política apresenta o momento certo para a mudança na política pública, e as restrições potenciais não são severas.... Empreendedores de política desempenham o papel principal na combinação dos fluxos na janela de política aberta, ligando soluções a problemas, sobrepujando as restrições pela mudança nas propostas, e tirando vantagem de eventos politicamente favoráveis (Kingdon, 2003, p. 165).

A combinação de pelo menos dois fluxos permite colocar um problema na agenda governamental, mas as probabilidades deste entrar na agenda decisional aumentam muito se os três fluxos forem combinados (Kingdon, 2003). As janelas de oportunidade ou policy windows que se abrem irão permitir que itens na agenda decisional sejam transformados em políticas, e os membros da comunidade de política investem seus recursos para que suas propostas ganhem prioridade. De acordo com Kingdon (2003), as agendas são afetadas, sobretudo, pelos fluxos de problemas e político, enquanto que as alternativas, pelo fluxo de política ou de soluções; o fluxo de políticas ou de soluções gera, permanentemente, ideias de políticas públicas em torno do governo e demais atores envolvidos na formulação de políticas: são soluções em busca de um problema que, quando eventos no fluxo político permitem, adentram a agenda política por meio de uma janela. Esta se abre, para o autor, por causa de problemas que exigem ação imediata do governo (ou, no mínimo, parecem fazê-lo), por mudanças no governo, no humor nacional ou pela entrada de novos parlamentares no Poder Legislativo; Birkland (1998 como citado em Howlett \& Ramesh, 2003) adiciona os ciclos orçamentários à lista de eventos que favorecem a abertura de janelas de oportunidades. Quando as janelas se abrem, defensores (advocates) de determinadas propostas sentem a oportunidade e buscam aproveitá-la, colocando problemas para a deliberação dos tomadores de decisão ou apresentando suas alternativas de solução.

Em sua análise do modelo de Kingdon (2003), Howlett e Ramesh (2003) reconhecem quatro tipos de janelas, ordenadas crescentemente de acordo com seu grau de institucionalização e previsibilidade (quanto mais institucionalizada for uma janela, maior é a previsibilidade de sua abertura): 
1. Janelas aleatórias: eventos aleatórios ou crises abrem janelas imprevisíveis.

2. Janelas discricionárias: o comportamento de atores políticos individuais conduz à abertura da janela.

3. Janelas de externalidade: questões relacionadas a algum assunto que já possua uma janela aberta conduzem à abertura de uma nova janela.

4. Janelas rotinizadas: procedimentos e eventos institucionais (como os orçamentos e as eleições) fazem com que uma janela se abra.

O modelo de Kingdon não está isento de críticas; para combatê-las, Zahariadis (1998) o trabalhou empiricamente em seu estudo da privatização na Inglaterra e na França não apenas na montagem de agenda, ampliando-o para abranger a tomada de decisão. Em seu modelo original, Kingdon (2003) não tratava do processo decisório, usando a teoria do garbage can de Cohen, March e Olsen como recurso heurístico para a explicação do processo decisório; Zahariadis (1998), por sua vez, considera essa teoria da decisão como insuficiente para compreender as escolhas organizacionais no seio dos governos, devido às restrições que os tomadores de decisão enfrentam em suas organizações. Assim, em vez de adotá-la, ele opta por ampliar o alcance do modelo.

Para Zahariadis (1998), é possível considerar a montagem da agenda, que ele concebe como o processo pelo qual determinadas questões ganham proeminência, como autônoma em relação à especificação de alternativas de solução - mas não se pode separar essa atividade da escolha efetiva de uma alternativa, pois ambas são momentos do processo de tomada de decisão. Dessa maneira, a tomada de decisão é definida pelo autor como "o processo pelo qual formuladores de política fazem, com autoridade, uma escolha a partir de um conjunto limitado de alternativas previamente geradas" (Zahariadis, 1998, p. 34). Considerar a formulação de alternativas e a decisão propriamente dita como momentos de um mesmo processo é um recurso que, de acordo com este autor, foi adotado pela maioria das teorias de formulação de política. A segunda modificação importante que ele opera no modelo é a não diferenciação entre os participantes e os processos; de acordo com ele, os burocratas, por exemplo, tendem a ser mais relevantes na formulação de alternativas (ou seja, no fluxo de políticas), enquanto que líderes políticos atuam no fluxo político, tornando pouco produtiva a separação entre processos e participantes. Em terceiro lugar, os elementos do fluxo político (humor nacional, forças políticas organizadas e mudanças políticas) são combinados no conceito de ideologia e estratégia dos partidos governantes.

\section{Procedimentos Metodológicos}

O presente trabalho é de natureza qualitativa e não experimental e foi construído a partir da perspectiva de um estudo de caso descritivo. A pesquisa se classifica como qualitativa devido ao seu foco nas relações sociais, nas interações entre os participantes do processo decisório no Comitê Itajaí e na perspectiva adotada por estes ao lidarem com a questão da cobrança (Flick, 2009). O caráter descritivo se justifica pelo seu foco num fenômeno específico (a decisão de cobrança) e o uso de informações contextuais para sua análise (Deslauriers \& Kérisit, 2008).

A escolha do Comitê Itajaí como objeto de estudo para o presente artigo deu-se pelas seguintes razões: em primeiro lugar, trata-se de organização que vem operando ininterruptamente desde 1998; em segundo lugar, entre os comitês localizados em Santa Catarina, este se mostra o mais atuante e o mais adiantado em termos de discussão dos instrumentos de gestão de recursos hídricos; em terceiro lugar, a própria região de atuação do Comitê é extremamente significativa, pois nela habitam mais de 1.250.000 pessoas, de acordo com dados do Instituto Brasileiro de Geografia e Estatística (IBGE, 2010), distribuídas em seus 50 municípios, destacada pelo forte capital social; por fim, o Comitê encontra-se localizado em região de intenso desenvolvimento econômico, destacando as indústrias têxtil e metal- 
mecânica e a agropecuária. Nesse aspecto, merece destaque, ainda, o fato de o Porto de Itajaí ser o segundo maior do Brasil em movimentação de contêineres (Porto de Itajaí, n.d.).

Como instrumentos de coleta de dados, usaram-se a análise documental e a entrevista. A análise documental concentrou-se nos documentos oficiais do Comitê Itajaí e em suas atas de assembleias, estas coletadas desde a fundação do órgão. No total, foram analisadas 47 atas de assembleias gerais ordinárias e extraordinárias, cobrindo o período 1999 - 2010, ou seja, o período em que o assunto cobrança começa a ser discutido e a efetiva aprovação do Plano de Bacia. Quanto aos demais documentos oficiais, foram analisadas 39 deliberações e resoluções, além de 12 moções, mas poucos dados relevantes foram observados para a solução do problema de pesquisa. Na análise documental, foi possível perceber que o tema da cobrança vinha sendo trazido à baila desde o início das atividades do comitê, mas era relativamente pouco discutido no plenário; quanto às resoluções e moções, seu conteúdo era bastante variado: muitas tratavam de questões referentes à organização interna do órgão, outras apresentavam solicitações ao Poder Público estadual e municipal, e algumas deliberavam sobre a composição de câmaras e comissões, vendo-se nestas a preocupação com o uso do conhecimento de especialistas e acadêmicos nos trabalhos.

Buscou-se identificar, nas atas, a participação de diferentes atores no processo de discussão e de tomada de decisão da cobrança, no intuito de verificar até que ponto estes atores tentavam definir os rumos da discussão e fazer prevalecer seus pontos de vista sobre o instrumento. A análise de conteúdo dos documentos foi heurística (Bardin, 2009), com a intenção de gerar descobertas a serem aprofundadas posteriormente.

Já a entrevista foi realizada com uma amostra de 11 representantes dos diferentes segmentos (população, usuários e poder público) que têm assento no órgão. A amostra foi por acessibilidade, haja vista que as dificuldades de contatar os representantes e definir datas para a realização das entrevistas presenciais e estruturadas exigiram que, uma vez que uma pessoa se dispusesse a dar a entrevista, o pesquisador fosse em seu contato e realizasse a mesma. Limitações de tempo restringiram a amostra a 10 representantes dos usuários, da população da bacia e do poder público, aos quais se soma a $11^{\mathrm{a}}$ entrevista, feita por e-mail e realizada junto a um dos pesquisadores que fizeram parte da equipe responsável pela montagem da fórmula e do modelo de cobrança.

As entrevistas foram semiestruturadas, contando com um roteiro de 15 perguntas padronizadas, tendo sido acrescentados novos questionamentos sempre que necessário. As entrevistas foram gravadas com a anuência dos entrevistados, e sua transcrição devidamente validada após a realização, foi autorizado seu uso na íntegra pelos vários entrevistados, registrando-se apenas dois casos em que se solicitou fazer mudanças de pequena monta nas transcrições. As entrevistas foram realizadas em diferentes locais, conforme a conveniência dos entrevistados, e duraram em torno de 40 minutos cada uma. Infelizmente, limitações na agenda dos entrevistados tornou impossível a realização de maior número de entrevistas, assim, impondo uma restrição ao alcance das conclusões deste artigo, que devem ser consideradas como observações preliminares sobre a aplicabilidade do modelo de Kingdon ao caso em tela.

\section{A Montagem de Agenda na Decisão de Cobrança no Comitê Itajaí}

O Comitê Itajaí foi criado oficialmente pelo Decreto Estadual n. 2.109, em 5 de agosto de 1997, e sua instalação deu-se em 12 de março de 1998, quando foi eleita a primeira diretoria (Bohn \& Correia, 1998; Uller-Gómez, 2006), embora o grupo de trabalho que o criou viesse realizando atividades e workshops antes mesmo de sua fundação oficial. O Comitê atua em um território que abrange total ou parcialmente a área de 58 municípios, mas apenas 50 estão nele representados, conforme se encontra disposto em seu Regimento Interno (Comitê do Itajaí, 2005). 
Entre seus objetivos, destacam-se a preocupação com o gerenciamento descentralizado, participativo e integrado dos recursos hídricos, a caracterização da água como bem público de valor econômico, a preocupação com a cobrança e o rateio dos custos, o desenvolvimento regional e sustentável e a prioridade do atendimento às necessidades da população, aspectos que seguem os ditames da Lei n. 9.433 (1997). No que tange às competências, evidencia-se a preocupação com estabelecer debates em torno de instrumentos de gestão, como o Plano de Recursos Hídricos, a geração de informações para o Sistema de Informações de Recursos Hídricos, o enquadramento e a cobrança pelo uso de recursos hídricos, subsidiar as decisões referentes a obras na região da bacia e com aspectos ambientais e de desenvolvimento sustentável. Há, também, o cuidado com a compatibilização de interesses de diferentes usuários, atuando para dirimir os conflitos entre eles.

O comitê possui uma Assembleia Geral formada por 50 membros, dos quais 20 são representantes dos usuários de água, 20 da população da bacia e 10 são representantes das administrações públicas federal e estadual; é o órgão deliberativo soberano. Além disso, possui uma Presidência assessorada por uma Comissão Consultiva de nove membros, igualmente distribuídos entre os diferentes tipos de representantes, e por uma Secretaria Executiva, órgão essencialmente técnico, bem como por Câmaras Técnicas (CT) criadas para finalidades específicas (como a CT-Plan e a CT-Cheias, voltadas respectivamente para o planejamento e para o monitoramento das cheias, problema recorrente na bacia).

Pode-se também observar que o Comitê Itajaí, ao formar grupos de trabalho e câmaras técnicas para apreciar questões específicas, segue exatamente a caracterização que Sartori (1994) fez de um comitê: as câmaras e grupos se reúnem como grupos menores para apreciar assuntos e temas que devem ser, posteriormente, levados ao grupo maior - neste caso, à plenária. Os grupos de trabalho na elaboração do Plano operavam com objetivos claramente definidos, e seus membros discutiam entre si o que seria feito, sendo posteriormente levados os resultados à diretoria e plenária para decisão final. O grupo de trabalho para a cobrança ilustra bem essa questão: formado sob os auspícios do órgão maior, reuniu-se para discutir qual seria a melhor forma de instituir essa prática na bacia do Itajaí, e levou seu relatório para a apreciação e decisão final de todos os membros do Comitê. Como se observa na fala do entrevistado 6 (Usuários), a decisão de subdividir o setor industrial em segmentos menores e modificar os coeficientes setoriais $\left(\mathrm{K}_{\mathrm{s}}\right)$, de modo a diferenciar o ônus, ilustra a noção sartoriana.

É interessante considerar que tanto o Comitê quanto o grupo de trabalho que lidou com a fórmula podem ser caracterizados como arenas decisórias, mas não se pode descrever adequadamente o funcionamento do grupo específico, pois este não foi objeto das entrevistas nem se encontra descrito na documentação oficial do órgão. Essas arenas são espaços públicos, na definição de Dagnino (2002), haja vista que estabelecem um espaço de convivência entre atores com diferentes interesses, democraticamente regulado, administram conflitos e buscam construir consensos.

Assim, em termos das definições adotadas aqui para caracterizar as arenas decisórias, tem-se, para o Comitê Itajaí:

1. Atores: podem ser circunscritos aos representantes de usuários, da população e dos órgãos públicos que têm assento no Comitê de bacia. Entre esses atores, pode-se identificar a diretoria do órgão como possuidora de uma característica especial: os diretores são todos representantes dos diferentes segmentos, têm a responsabilidade última pelas decisões. Além disso, representam não apenas os interesses desses segmentos, mas também os do Comitê como organização. Eventualmente, atores que não fazem parte do órgão se mostram importantes, como os membros do Conselho Estadual de Recursos Hídricos, da Secretaria do Desenvolvimento Econômico e Sustentável, etc.

2. Espaço institucional: a plenária do Comitê, em que são apreciados os assuntos e temas já definidos nos grupos de trabalho. Seguem-se as regras definidas pela legislação federal, pois, como se pode observar na fala de alguns dos entrevistados e a análise da bibliografia demonstrou, há lacunas na legislação estadual em relação ao funcionamento desse órgão, bem como uma definição adequada de seu espaço na gestão de recursos hídricos em nível estadual. 
3. Situações-problema: pode-se considerar que a aprovação do plano como um todo seja uma situaçãoproblema geral, mas é mais interessante trabalhar com a definição, aprovação e implementação de uma fórmula de cobrança como sendo a situação mais relevante para este estudo.

4. Soluções satisfatórias: pelas características do processo decisório, é impossível identificar, aqui, a ideia de um modelo de ator racional. Não há possibilidade de maximização de interesse porque a composição do Comitê não permite que um grupo prepondere sobre os demais, a menos que sejam constituídas coalizões, mas este fenômeno não foi estudado. Assim, pode-se considerar que a solução satisfatória seria aquela que permitiria a implantação de um modelo de cobrança que não onerasse demasiadamente os usuários, apresentasse baixo custo político e fornecesse recursos financeiros suficientes para que as obras da bacia, que se supõem serem de interesse de todos, fossem realizadas.

5. Interesses: correndo-se o risco de simplificar em demasia a realidade, pode-se dizer que o segmento de usuários tem interesse em pagar o mínimo possível pela água utilizada em seus processos produtivos; o segmento do poder público não parece ter um interesse facilmente identificável, até por sua heterogeneidade, já que abrange órgãos estaduais e federais: o entrevistado 11 (População) deixou claro que, em sua opinião, o governo do Estado não tem interesse em instituir a cobrança sem receber recursos, mas essa ideia não aparece no discurso do entrevistado 10 (Poder Público), que é membro de uma organização estadual - o que não significa descartar de todo essa possibilidade. Verificou-se, também, a existência de algumas reservas, manifestadas numa das atas por um dos prefeitos da região, bem como pelo entrevistado 11 (População), que atualmente é prefeito de uma das cidades. Não foi possível localizar nenhum representante de órgãos federais, mas supõe-se que esta esfera de poder público apoie a legislação federal. Finalmente, no que diz respeito aos representantes da população, os entrevistados parecem ter interesse na instituição da cobrança para que se possa viabilizar financeiramente um conjunto de obras na bacia. Entretanto é importante mencionar a fala do entrevistado 2 (População): os usuários se mostraram unidos na defesa de seus interesses, enquanto que as ONGs defendiam interesses apenas nas suas respectivas áreas de atuação.

O Comitê, na elaboração do Plano de Bacia, trabalhou com uma agenda definida pela Lei n. 9.433 (1997). Não se trata de imposição, meramente, mas de aceitação dessa agenda, uma vez que o órgão se formou a partir da organização da sociedade local, a partir dos estudos e das análises da Universidade Regional de Blumenau (Furb), que buscava, dessa forma, minorar o problema das enchentes na região. No entanto, desde o início, o Comitê buscou se aproximar do empresariado, pois sua presidência foi originalmente ocupada por um grande empresário da região; esta aproximação foi confirmada por diferentes entrevistados.

Deve-se observar que os entrevistados foram categóricos em declarar que sempre havia um espaço para a modificação da agenda de discussão: havia sempre abertura para introduzir novos assuntos, seja nas reuniões das Câmaras Técnicas e dos Grupos de Trabalho, seja nas assembleias gerais. É interessante notar que alguns dos representantes dos usuários entrevistados, mormente o entrevistado 3 e o 6 , observaram que pouco se usava esse espaço, e que os usuários, embora considerados bem organizados pelos demais, não aproveitavam o espaço para introduzir nas discussões os temas que julgavam importantes.

Originalmente, o Comitê propôs uma equação de composição da cobrança, advinda das discussões na Câmara Técnica e baseada em trabalho realizado por um economista estudioso do assunto e devidamente contratado para este fim. Esta equação se caracterizava por diferenciar pouco ou quase nada as especificidades dos usuários, pois apenas um coeficiente de participação do segmento usuário $\left(\mathrm{K}_{\text {seg }}\right)$ permitia a distinção dos vários usuários. Os demais parâmetros se referiam aos valores de cobrança para captação, consumo e lançamento, à emissão de efluentes, às classes de enquadramento dos cursos d'água e aos valores de cobrança em diferentes pontos da bacia.

Esta proposta foi apresentada e gerou intensa discussão, para cuja análise utiliza-se o modelo de Kingdon (2003) de montagem de agenda. Deve-se, inicialmente, considerar que, para o Comitê, esta era formada pela elaboração, aprovação e implantação do Plano de Bacia e de seus instrumentos, incluindo- 
se aí, evidentemente, a cobrança pelo uso de recursos hídricos. Considerando-se a classificação de Birkland (2005), tem-se:

1. Universo de agenda: conjunto de práticas de gestão ambiental no seu sentido mais amplo, uma vez que essas diferentes práticas têm impactos sobre a qualidade e a quantidade de recursos hídricos da bacia.

2. Agenda sistêmica: conjunto de instrumentos e práticas de gestão de recursos hídricos, conforme contemplados pelos conhecimentos técnicos e científicos da área, bem como os saberes tradicionais das comunidades.

3. Agenda institucional: instrumentos e práticas de gestão previstos na Lei n. 9.433 (1997).

4. Agenda de decisão: no caso, praticamente idêntica à agenda institucional, diferencia-se desta por ser composta pelos instrumentos e práticas de gestão devidamente adaptados à realidade da bacia. Assim, por exemplo, no que diz respeito ao enquadramento, é preciso considerar a realidade dos rios da bacia, bem como os objetivos que se deseja atingir em termos de qualidade e quantidade de águas no futuro.

Verifica-se que, no Comitê, não há o monopólio de agenda definido por Majone (2006) - embora fique nítido que boa parte dela provenha da diretoria do órgão e dos grupos de trabalho que esta criou para lidar com os diferentes elementos do Plano - porque havia a abertura para inclusão de itens na pauta, o que foi evidenciado por meio da fala dos entrevistados. No entanto é preciso que se diga que a agenda institucional estava praticamente engessada pela legislação, pois o Plano de Bacia não pode ser implantado sem que os instrumentos por ele contemplados estejam devidamente definidos, regulados e aprovados. Dessa forma, há uma situação de "quase monopólio" na formação da agenda do Comitê. É digno de nota observar que, na assembleia que aprovou o Plano, houve defesa no sentido de que a cobrança fosse ainda mais discutida, conforme a ata - mas a diretoria propôs que aquele fosse aprovado, e a fórmula de cobrança mudada posteriormente. A diretoria, neste caso, pode ter agido como Kingdon (2003) observou: em vez de ampliar a discussão, apresentou uma proposta que pudesse satisfazer a todos.

Concentrando-se na agenda de decisão no caso da cobrança, pode-se afirmar que se trata do conjunto dos elementos que, na cobrança, precisam ser debatidos e formalmente decididos, quais sejam, de quem cobrar, quanto cobrar, quando cobrar e como cobrar. A agenda de decisão possui uma série de elementos, no modelo de Kingdon (2003), que podem ser exemplificados a partir da subdivisão do coeficiente setorial $\left(\mathrm{K}_{\mathrm{s}}\right)$ da indústria em coeficientes particulares para os diferentes subsetores da indústria:

1. Fluxo de problemas: a subdivisão do coeficiente da indústria chamou atenção dos tomadores de decisão por conta do feedback dado pelos usuários do setor, que demonstraram sua insatisfação com a proposta original. Ficou claro, para a diretoria do Comitê, que a proposta original de um só coeficiente para toda a indústria não angariava apoio dos representantes de usuários e não seria aprovada. Seguindo-se a análise de Chow (2014), constatou-se, aqui, que o fluxo de problemas pode ser considerado, de um lado, a necessidade de aprovar uma fórmula por parte da diretoria e, de outro, a busca por uma solução satisfatória (Stone, 2002) por parte dos representantes dos usuários. Não existem elementos que apoiem a ideia de mudança nos indicadores, nem eventos focalizadores (Kingdon, 2003) que levem a essa modificação - a menos que se coloque a aprovação do Plano de Bacia como um evento focalizador, mas não se adota esta perspectiva por se compreendê-la como um processo multifacetado, não como um evento.

2. Fluxo de políticas ou soluções: é possível identificar dois grandes grupos de comunidades de política no sentido dado por Kingdon (2003), o grupo de trabalho formado pelo próprio Comitê, antes da votação do Plano (que incluiu o entrevistado 8 - Pesquisador), responsável pela formulação de um modelo de cobrança que foi incorporado na proposta originalmente apresentada e votada na Assembleia Geral Extraordinária n. 23 (2010 como citado em Zapelini, 2012), e o grupo de trabalho 
formado pelos usuários para a formulação de uma contraproposta. É possível que a diretoria já antecipasse dificuldades em termos de viabilidade, aceitação e eficiência da proposta original, bem como estivesse prevendo problemas em sua aprovação, mas não se dispõe de elementos para sustentar este ponto de vista. O grupo do Comitê apresentava como solução para o problema dos valores da cobrança uma fórmula mais simples, enquanto que o dos usuários propunha uma solução um pouco mais complexa, mas mais aceitável em termos de contemplar os interesses dos diferentes subgrupos industriais. A proposta do Comitê constava do Plano originalmente aprovado, e a do grupo de trabalho foi apresentada posteriormente, restringindo as soluções em análise a um número muito menor do que poderia compor o total possível.

3. Fluxo político: pode-se dizer que, pelas evidências obtidas com a análise das entrevistas e das atas, o humor nacional (Kingdon, 2003) do Comitê era favorável à cobrança enquanto instrumentos, mas não havia consenso em relação à forma que esta assumiria. As pressões de forças políticas organizadas podem ser descritas em termos da atuação do segmento dos usuários, notadamente dos representantes dos industriais, para garantir uma fórmula mais adequada aos seus interesses, pois há várias menções nas atas a questionamentos e críticas à cobrança. Não há, aqui, mudança na composição da diretoria (fazendo as vezes de corpo legislativo, conforme Kingdon, 2003) do Comitê que justifique a análise do terceiro elemento deste fluxo, as mudanças no governo e na administração (como apontado, entre outros, por Blankenau, 2001), mas pode-se lembrar, novamente usando a perspectiva de análise de Chow (2014), que uma parte considerável dos representantes apoiava a proposta da diretoria, enquanto que outros defendiam a dos usuários.

4. Empreendedores de política: Kingdon (2003) e Travis e Zahariadis (2002) descrevem-os como aqueles que dispõem de tempo, recursos, energia e interesses para investir na policy-making. Dentro desta lógica, podem ser descritos como os dois grupos de trabalho, tanto aquele que foi originalmente constituído pelo Comitê para estudar o tema quanto o que foi criado após a aprovação do Plano para rediscutir a cobrança, mas também podem ser reconhecidos como a diretoria do órgão e os representantes dos usuários. De maneira menos institucionalizada, os representantes dos usuários, reconhecidos pelos entrevistados como os mais organizados entre os membros do Comitê, atuaram como empreendedores, sobretudo nas assembleias de aprovação do Plano de Bacia: a mobilização de discursos e de ideias definida por Bakir (2009) pode ser encontrada na declaração de um dos representantes dos usuários, que afirmou durante a Assembleia Geral Extraordinária n. 23 não ser contrário à cobrança, e sim à fórmula usada. Entretanto não se encontrou evidência de ação dos empreendedores como implementadores de política, conforme defendido por Lima e Medeiros (2012).

O resultado do coupling dos fluxos foi a inclusão, na agenda do Comitê, de um debate mais profundo do problema da cobrança, que tencionava chegar a um modelo que simultaneamente cumprisse os objetivos propostos no Plano para esse instrumento e atendesse aos interesses dos usuários do segmento industrial. A janela de oportunidade se abriu quando do impasse em relação à aprovação do Plano: ao se decidir aprovar a ideia de implantar a cobrança, mas com a promessa de rediscutir a fórmula para acomodar os interesses dos usuários, abriu-se uma chance deste grupo de empreendedores de política de influenciar os rumos do instrumento e defini-lo dentro de seus interesses e necessidades, agindo, assim, como advocates no sentido definido por Kingdon (2003). A proposta era viável, dentro da formulação de Blankenau (2001), já que uma solução alternativa, proveniente dos usuários, estava de acordo com o fato de estes terem desempenhado historicamente um papel importante na gestão do Comitê.

A janela aberta pode ser descrita como discricionária, para se usar a classificação proposta por Howlett e Ramesh (2003): pode-se supor que tenha sido o comportamento dos representantes dos usuários na assembleia de aprovação do Plano que abriu a janela de oportunidade; a diretoria, percebendo que não conseguiria instituir a cobrança, acede ao pedido para maior discussão. Evidentemente, é bem possível que ela já considerasse essa hipótese antes mesmo da manifestação dos representantes de usuários, o que exigiria modificações na análise, mas não a invalidaria. 
O resultado dessa abertura de janela, devidamente aproveitada pelos atores e empreendedores de política descritos, foi que o plano de bacia hidrográfica foi aprovado com a ressalva de que a fórmula de cobrança deveria ser modificada. E, de fato, esse objetivo foi logrado pelos empreendedores, haja vista que uma nova fórmula foi aprovada, contendo a definição de coeficientes setoriais $\left(\mathrm{K}_{\mathrm{S}}\right)$, como pretendido por eles.

Decidiu-se utilizar uma fórmula baseada no valor adicionado pelo setor, conforme a proposição do setor usuário, que aproveitou a oportunidade para fazer valer sua ideia de um ônus diferenciado. Os coeficientes $\mathrm{K}_{\mathrm{S}}$ foram definidos para os diferentes setores da seguinte maneira: 0,1, para irrigação e aquicultura; 0,2 para criação de animais; 0,4 para abastecimento; 0,3 para os outros usos; e entre 0,6 e 1,0 para a indústria, conforme os subsetores: 0,6 para madeira, vestuário e outras indústrias; 0,7 para papel e celulose; 0,8 para metalurgia; 0,9 para têxtil; 1,0 para frigoríficos. Para o setor de energia elétrica, calculou-se o coeficiente $\mathrm{K}_{\mathrm{S}}$ em 0,6, e, para o setor portuário, não foi feito o cálculo. No entanto devese observar que o coeficiente calculado para a energia elétrica não seria aplicado porque o setor possui regulamentação específica, e que se sugeria o valor 1,0 para o do saneamento, pois se trata de um uso prioritário e porque o esgoto sanitário é o principal responsável pela baixa qualidade da água, de acordo com informações obtidas na Ata da Assembleia Geral Extraordinária n. 23 (2010 como citado em Zapelini, 2012).

A discussão da cobrança pelo uso dos recursos hídricos no Comitê Itajaí pode ser usada como evidência da forma com que os empreendedores de política observam oportunidades para influenciar as decisões finais, fazendo valer seus pontos de vista, mesmo num espaço democrático e participativo. Assim, pode-se considerar que o modelo de Kingdon se mostra uma ferramenta relevante para a análise da montagem de agenda no caso estudado.

\section{Considerações Finais}

O presente trabalho possui limitações, como o pequeno número de representantes do Comitê entrevistados, que impedem a generalização das conclusões alcançadas, e deve ser interpretado como uma tentativa de aplicação de um referencial teórico a um caso empírico, aplicação esta ainda em construção e que poderá sofrer modificações futuras com base em novas descobertas de pesquisa. Entretanto os principais aspectos do modelo são confirmados pelo caso estudado, destacando-se que se trata da aplicação de um modelo a um órgão público, porém não governamental.

John Kingdon definiu seu modelo de montagem de agenda a partir de seus estudos sobre o processo de definição das agendas de discussão no Congresso norte-americano. Quase 30 anos depois da publicação da edição original de seu livro, e passados quase 15 anos da revisão de seu modelo de análise por Zahariadis, o modelo ainda permanece muito discutido, mas relativamente pouco aplicado em casos empíricos (algo que Zahariadis, 1998, lamentou). No caso do Comitê Itajaí, percebe-se que o espaço do órgão em elaborar e discutir uma agenda é relativamente restrito, uma vez que se encontra limitado pelas exigências e ditames da legislação. No entanto isso não significa que não haja a possibilidade de montar agendas de discussão a partir dos temas previamente definidos, como o caso da cobrança demonstra claramente.

Kingdon (2003) observa que grupos bem organizados, definidos a partir da defesa de seus interesses, podem operar como empreendedores de política, aproveitando que os três fluxos se encontram em momentos especiais. No caso estudado, a discussão e aprovação do plano de bacia, em 2010, revelou-se o momento ideal para trazer modificações à fórmula de cobrança originalmente definida, de modo a garantir que a mesma refletisse melhor os interesses e necessidades de um dos principais grupos envolvidos no processo, os usuários. As entrevistas realizadas (contrariamente aos registros de atas) demonstraram haver, entre os representantes, consciência da importância e da necessidade do instrumento, mas não o consenso sobre como fazê-lo. No momento em que se parecia encaminhar a aprovação integral do plano, os empreendedores de política do setor dos usuários 
aproveitaram a janela de oportunidade e levaram o Comitê a abandonar sua formulação original para a cobrança e aceitar sua modificação, constituída com a participação efetiva de representantes desses empreendedores.

Dessa maneira, pode-se tirar uma importante lição do caso: uma vez que as oportunidades surgem, grupos bem organizados tiram proveito delas para rediscutir ou modificar questões e aspectos que aparentemente já eram consensuais. Assim, as agendas nunca estão definitivamente fechadas.

\section{Referências}

Bachrach, P., \& Baratz, M. S. (1962). Two faces of power. The American Political Science Review, 56(4), 947-952. Retrieved from http://www.columbia.edu/itc/sipa/U6800/readingssm/bachrach.pdf. doi: http://dx.doi.org/10.2307/1952796

Bakir, C. (2009). Policy entrepreneurship and institutional change: multilevel governance of central banking reform. Governance: an international journal of policy, administration and institutions, 22(4), 571-598. doi: 10.1111/j.1468-0491.2009.01454.x

Bardin, L. (2009). Análise de conteúdo. Lisboa: Edições 70.

Birkland, T. A. (2005). An introduction to the policy process: theories, concepts, and models of public policymaking (2nd ed.). Armonk: M. E. Sharpe.

Blankenau, J. (2001). The fate of national health insurance in Canada and the United States: a multiple streams explanation. Policy Studies Journal, 29(1), 38-55. doi: 10.1111/j.15410072.2001.tb02073.x

Bohn, N., \& Correia, M. A. (1998, outubro). Contribuição para o aprimoramento e a implementação da legislação de recursos hídricos - o caso do Comitê do Itajaí. Anais do Simpósio Internacional sobre Gestão de Recursos Hídricos, Gramado, RS, Brasil.

Capella, A. C. (2007). Perspectivas teóricas sobre o processo de formulação de políticas públicas. In G. Hochman, M. Arretche, \& E. Marques (Orgs.), Políticas públicas no Brasil (pp. 87-122). Rio de Janeiro: Fiocruz.

Chow, A. (2014). Understanding policy change: multiple streams and national education curriculum policy in Hong Kong. Journal of Public Administration and Governance, 4(2), 49-64. doi: 10.5296/jpag.v4i2.5184

Comitê do Itajaí. (2005). Regimento do comitê de gerenciamento da bacia hidrográfica do Rio Itajaí. Recuperado de http://www.comiteitajai.org.br/portal/index.php/regimento.html

Dagnino, E. (2002). Sociedade civil e espaços públicos no Brasil. In E. Dagnino (Org.), Sociedade civil e espaços públicos no Brasil (pp. 9-15). São Paulo: Paz e Terra.

Deslauriers, J. P., \& Kérisit, M. (2008). O delineamento da pesquisa qualitativa. In J. Poupart, J.-P. Deslauriers, L.-H. Groulx, A. Laperriére, R. Mayer, \& A. P. Pires, A pesquisa qualitativa: enfoques epistemológicos e metodológicos (pp. 127-153). Petrópolis: Vozes.

Dias, T. F., \& Barros, H. de (2008, novembro). Gestão de recursos hídricos: um olhar para visões da cobrança pelo uso da água a partir dos membros do Comitê de Bacia Hidrográfica do Rio Pirapama - PE. Anais do Encontro de Administração Pública e Governança, Salvador, BA, Brasil, 3.

Flick, U. (2009). Desenho da pesquisa qualitativa. Porto Alegre: Artmed. 
Hollis, M. (1999). Agendas. In S. H. Heap, M. Hollis, B. Lyons, R. Sugden, \& A. Weale (Eds.), The theory of choice: a critical guide (pp. 229-258). Oxford: Blackwell Publishers.

Howlett, M., \& Ramesh, M. (2003). Studying public policy: policy cycles and policy implementation (2nd ed.). Ontario: Oxford University Press Canada.

Hunt, R. G., \& Magenau, J. M. (1984). A task analysis strategy for research on decision making in organizations. In L. G. Nigro (Ed.), Decision making in the public sector (pp. 117-150). New York: Marcel Dekker.

Instituto Brasileiro de Geografia e Estatística. (2010). Sinopse do censo demográfico 2010 Santa Catarina. http://www.censo2010.ibge.gov.br/sinopse/index.php?uf=42\&dados=11

Jacobi, P. R. (2006a). Gestão participativa das águas. São Paulo: Procam/USP.

Jacobi, P. R. (2006b). Participação na gestão ambiental no Brasil: os comitês de bacias hidrográficas e o desafio do fortalecimento de espaços públicos colegiados. In H. Alimonda (Ed.), Los tormentos de la matéria:aportes para uma ecologia política latino-americana (pp. 205-230). Recuperado de http://bibliotecavirtual.clacso.org.ar/ar/libros/grupos/hali/C7PJacobi.pdf

Jones, B. D., \& Baumgartner, F. R. (2004). Representation and agenda setting. The Policy Studies Journal, 32(1), 1-24. doi: 10.1111/j.0190-292X.2004.00050.x

Kingdon, J. W. (2003). Agendas, alternatives, and public policies (2nd ed.). New York: Longman.

Lei n. 9.433, de 08 de janeiro de 1997. (1997). Institui a política nacional de recursos hídricos, cria o sistema nacional de gerenciamento de recursos hídricos, regulamenta o inciso XIX do art. 21 da Constituição Federal, e altera o art. 1o da Lei No 8.001, de 13 de março de 1990, que modificou a Lei No 7.990, de 28 de dezembro de 1989. Recuperado de http://www.planalto.gov.br/ccivil_03/LEIS/L9433.htm

Lima, M. L. O. F. de, \& Medeiros, J. J. (2012). Empreendedores de políticas públicas na implementação de programas governamentais. Revista de Administração Pública, 46(5), 1251-1270. doi: $10.1590 / \mathrm{S} 0034-76122012000500004$

Majone, G. (2006). Agenda setting. In M. Moran, M. Rein, \& R. E. Goode (Eds.), The Oxford handbook of public policy (pp. 228-250). Oxford: Oxford University Press.

Ostrom, E. (2007). Institutional rational choice: an assessment of the institutional analysis and developmental framework. In P. A. Sabatier (Ed.), Theories of the policy process (pp. 21-64). Boulder: Westview Press.

Page, E. C. (2006). The origins of policy. In M. Moran, M. Rein, \& R. E. Goode (Eds.), The Oxford handbook of public policy (pp. 207-227). Oxford: Oxford University Press.

Porto de Itajaí. (n.d.). Histórico. Recuperado de http://www.portoitajai.com.br/novo/c/historia

Sartori, G. (1994). A teoria da democracia revisitada: o debate contemporâneo. São Paulo: Ática.

Schattschneider, E. E. (1975). The semisovereign people: a realist's view of democracy in America. Boston: Wadsworth Publishing.

Simon, H. A. (1997). Administrative behavior (4th ed.). New York: The Free Press.

Souza, C. (2007). Estado da arte da pesquisa em políticas públicas. In G. Hochman, M. Arretche, \& E. Marques (Orgs.), Políticas públicas no Brasil (pp. 65-86). Rio de Janeiro: Fiocruz. 
Stone, D. (2002). Policy paradox: the art of political decision making. New York: W. W. Norton \& Company.

Travis, R., \& Zahariadis, N. (2002). A multiple streams model of US foreign aid policy. Policy Studies Journal, 30(4), 495-514.

Uller-Gómez, C. (2006). Agricultura familiar e participação na gestão das águas na Bacia do Itajaí (SC, Brasil) (Tese de doutorado). Universidade Federal de Santa Catarina, Florianópolis, SC, Brasil.

Valencio, N. F. L. S. da (2009). Governança das águas: a participação social como quimera. In W. C. Ribeiro (Org.), Governança da água no Brasil: uma visão interdisciplinar (pp. 61-90). São Paulo: Annablume, Fapesp, CNPq.

Zahariadis, N. (1998). Markets, states, and public policy: privatization in Britain and France. Ann Arbor: The University of Michigan Press.

Zapelini, M. B. (2012). Poder e decisão na gestão de recursos hídricos: um estudo no Comitê Itajaí (Tese de doutorado). Universidade Federal da Bahia, Salvador, BA, Brasil. Recuperado de http://www.adm.ufba.br/sites/default/files/publicacao/arquivo/tese_de_marcello_zapelini_2012_ 05_31_v3.pdf 